\title{
Nanocomposites of Magnetite and Layered Double Hydroxide for Recyclable Chromate Removal
}

\author{
Gyeong-Hyeon Gwak, ${ }^{1}$ Min-Kyu Kim, ${ }^{1,2}$ and Jae-Min $\mathrm{Oh}^{1}$ \\ ${ }^{1}$ Department of Chemistry and Medical Chemistry, College of Science and Technology, Yonsei University, Wonju, \\ Gangwon-do 26493, Republic of Korea \\ ${ }^{2}$ Future Industries Institute, Division of Information Technology, Engineering and Environment, University of South Australia, \\ Mawson Lakes, SA 5095, Australia \\ Correspondence should be addressed to Jae-Min Oh; jaemin.oh@yonsei.ac.kr
}

Received 7 April 2016; Revised 19 September 2016; Accepted 11 October 2016

Academic Editor: Yu-Lun Chueh

Copyright (C) 2016 Gyeong-Hyeon Gwak et al. This is an open access article distributed under the Creative Commons Attribution License, which permits unrestricted use, distribution, and reproduction in any medium, provided the original work is properly cited.

\begin{abstract}
Nanocomposites containing magnetic iron oxide (magnetite) nanoparticles and layered double hydroxide (LDH) nanosheets were prepared by two different methods, exfoliation-reassembly and coprecipitation, for aqueous chromate adsorbent. According to X-ray diffraction, scanning electron microscopy, and atomic force microscopy, both nanocomposites were determined to develop different nanostructures; LDH nanosheets well covered magnetite nanoparticles with house-of-cards-like structure in exfoliation-reassembly method, while coprecipitation resulted in LDH particle formation along with magnetite nanoparticles. Zeta-potential measurement also revealed that the magnetite surface was effectively covered by LDH moiety in exfoliationreassembly compared with coprecipitation. Time, $\mathrm{pH}$, concentration dependent chromate adsorption tests, and magnetic separation experiments exhibited that both nanocomposites effectively adsorb and easily collect chromate. However, exfoliation-reassembly nanocomposite was determined to be slightly effective in chromate removal by $\sim 10 \%$. Chromate adsorbed nanocomposites could be regenerated by treating with bicarbonate and the regenerated nanocomposites preserved $\sim 80 \%$ of chromate adsorption efficacy after three times of recycling.
\end{abstract}

\section{Introduction}

Fabrication of nanocomposites is a subject of great importance in developing functional nanomaterials such as catalysts [1], nanomedicines [2], electronic materials [3], and pollutant scavenger [4]. Various kinds of nanomaterial components, such as 0-dimensional particles [5], 1-dimensional tubes [6] or fibers [7], and 2-dimensional nanosheets [8], have been utilized to fabricate nanocomposites having various functionalities. Especially, 2-dimensional nanosheets have attracted interests to prepare nanocomposites for catalysts [9], electrodes [10], and energy storage [11], due to their high specific surface area, unusual physicochemical property resulting from anisotropic structure, and controllable compositions. Among the 2-dimensional nanosheets, layered double hydroxides, LDHs: $\mathrm{M}(\mathrm{II})_{1-x} \mathrm{M}(\mathrm{III})_{x}(\mathrm{OH})_{2}\left(\mathrm{~A}^{n-}\right)_{x / n}$. $m \mathrm{H}_{2} \mathrm{O}$, (M(II): divalent metal cation; $\mathrm{M}(\mathrm{III})$ : trivalent metal cation; $\mathrm{A}^{n-}$ : anionic species with $n-$ charge, $0<x<$ $1 ; m$ : interlayer water quantity) have been widely studied in biomedical or environmental applications, as they have been reported to have biocompatibility [12], high anionic exchange capacity [13], tunable composition [14], and easy surface modification property [15]. As examples of LDHbased environmental remediation, nanoscale LDH reported by Goh et al. and hydrothermally prepared LDH reported by Wang et al. exhibited potential as chromate adsorbents with maximum efficacy of 33.8 and $12.15 \mathrm{mg} \mathrm{Cr}(\mathrm{VI}) / \mathrm{g} \mathrm{LDH}$, respectively $[16,17]$. Yu et al. studied the removal of $\operatorname{As}(\mathrm{V})$ and $\mathrm{Cr}(\mathrm{VI})$ with MgAl-LDH whose three-dimensional hierarchical structure affected removal efficiency showing maximum $\sim 150 \mathrm{mg} \mathrm{Cr}(\mathrm{VI}) / \mathrm{g} \mathrm{LDH}$ and $200 \mathrm{mg} \mathrm{As}(\mathrm{V}) / \mathrm{g} \mathrm{LDH} \mathrm{[18].}$

Despite the high adsorption capacity of LDHs on pollutants, there still remain drawbacks for practical application: difficulties in collection after pollutant treatment and low 
recyclability. Collection of adsorbents is a crucial factor in pollutant scavenger, especially for water treatment, in terms of preventing secondary pollution and recycling adsorbents. In this way, two strategies, introduction of magnetic properties to the LDHs [19-21] and fabrication of monoliths containing LDH moieties [22], have been suggested for easy collection. The first strategy, introduction of magnetic property to adsorbents, has been often reported due to effectiveness of magnetic separation. For this purpose, magnetic nanoparticles $\left(\mathrm{Fe}_{3} \mathrm{O}_{4}\right)$ are generally utilized to fabricate nanocomposite with $\mathrm{LDH}$. For instance, MgAl$\mathrm{LDH}$ nanoparticles were in situ grown on magnetic $\mathrm{CoFe}_{2} \mathrm{O}_{4}$ nanoparticles through coprecipitation by Deng et al. [19]. The nanocomposite showed chromate removal efficacy of $\sim 50 \mathrm{mg}$ $\mathrm{Cr}(\mathrm{VI}) / \mathrm{g}$ adsorbent at $200 \mathrm{ppm}$ chromate solution as well as preserved adsorption capacity up to 6 repeated adsorption tests. Similarly, ZnAl-LDH was introduced on magnetic $\mathrm{Fe}_{3} \mathrm{O}_{4}$ nanoparticles by coprecipitation [20], showing $20 \mathrm{mg} \mathrm{Cr}(\mathrm{VI}) / \mathrm{g}$ adsorbent at $800 \mathrm{ppm}$ chromate solution. Another literature reported $\mathrm{MgAl}-\mathrm{LDH} / \mathrm{Fe}_{3} \mathrm{O}_{4}$ nanocomposites prepared by coprecipitation, representing adsorption efficacy of $\sim 60 \mathrm{mg}$ dye (reactive red)/g adsorbent [21]. The other strategy of monolith fabrication has been scarcely reported. From our previous study, monolith-type nanocomposites having uniformly distributed MgAl-LDH nanoparticles in agarose scaffold have been developed for aqueous chromate removal, exhibiting $\sim 100 \mathrm{mg} \mathrm{Cr}(\mathrm{VI}) / \mathrm{g}$ adsorbent [22].

In this study, we are going to prepare nanocomposites consisting of magnetic $\mathrm{Fe}_{3} \mathrm{O}_{4}$ nanoparticles and MgAl-LDH nanosheets for potential chromate removal in water treatment. For this purpose, we applied two different strategies in preparing nanocomposites: coprecipitation of $\mathrm{MgAl}-\mathrm{LDH}$ on $\mathrm{Fe}_{3} \mathrm{O}_{4}$ nanoparticles as reported in other literatures [1921] and exfoliation-reassembly of MgAl-LDH nanosheets on $\mathrm{Fe}_{3} \mathrm{O}_{4}$ nanoparticles. The former technique is widely studied in LDH-based adsorbent; on the other hand, there are a few literatures for the latter. In fact, exfoliation-reassembly is often utilized strategy in preparing nanoparticle-graphene composites for catalyst or energy storage materials [23, 24]. As LDH has 2-dimensional structure-like graphite, exfoliation-reassembly can be applied for nanocomposites of $\mathrm{Fe}_{3} \mathrm{O}_{4}$ nanoparticles and LDHs. Materials characterization such as crystal structure, particle morphology, and surface charge on two kinds of nanocomposites will be described. In order to examine chromate removal capability of both nanocomposites, contact time, $\mathrm{pH}$, and concentration of chromate solutions were chosen as parameters. Furthermore, we collected nanocomposites by a magnet and repeated chromate adsorption test three times to evaluate recyclability of nanocomposites.

\section{Materials and Methods}

2.1. Materials. Magnesium nitrate hexahydrate $\left(\mathrm{Mg}\left(\mathrm{NO}_{3}\right)_{2}\right.$. $\left.6 \mathrm{H}_{2} \mathrm{O}\right)$, aluminum nitrate nonahydrate $\left(\mathrm{Al}\left(\mathrm{NO}_{3}\right)_{2} \cdot 9 \mathrm{H}_{2} \mathrm{O}\right)$, sodium bicarbonate $\left(\mathrm{NaHCO}_{3}\right)$, ferric chloride hexahydrate $\left(\mathrm{FeCl}_{3} \cdot 6 \mathrm{H}_{2} \mathrm{O}\right)$, ferrous chloride tetrahydrate $\left(\mathrm{FeCl}_{2} \cdot 4 \mathrm{H}_{2} \mathrm{O}\right)$, and potassium chromate $\left(\mathrm{K}_{2} \mathrm{CrO}_{4}\right)$ were purchased from
Sigma-Aldrich Co. LLC. (St. Louis, MO, USA). Sodium hydroxide $(\mathrm{NaOH})$ and ammonia water $\left(\mathrm{NH}_{4} \mathrm{OH}\right)$ were purchased from Duksan Pure Chemicals Company (Ansan, Korea). The deionized water (DI water) in all experiments was purified by Human Power II+ Water Purification System (Human Corporation, Seoul, Korea).

2.2. Preparation of Magnetite $\left(\mathrm{Fe}_{3} \mathrm{O}_{4}\right)$ Nanoparticles. For the preparation of magnetite nanoparticles (Mag), mixed iron precursor $\left(0.0263 \mathrm{mmol}\right.$ of $\mathrm{FeCl}_{3} \cdot 6 \mathrm{H}_{2} \mathrm{O}$ and $0.0132 \mathrm{mmol}$ of $\left.\mathrm{FeCl}_{2} \cdot 4 \mathrm{H}_{2} \mathrm{O}\right)$ was dissolved in DI water $(300 \mathrm{~mL})$ with vigorous stirring at $50^{\circ} \mathrm{C}$ and then $32 \mathrm{~mL}$ of ammonia solution $(6.64 \mathrm{M})$ was quickly added. After formation of black precipitates, the reactant was subjected to microwave treatment ( 2 minutes) for facilitated crystallization. Thus, obtained magnetite nanoparticles were centrifuged at $3500 \mathrm{rpm}$ for 10 minutes, washed with DI water/acetone $(1 / 1 \mathrm{v} / \mathrm{v} \%) 3$ times, and then dried in vacuo.

2.3. Preparation of Magnetite @ Layered Double Hydroxide (Mag@LDH) Nanocomposites with Two Different Methods ((1) Exfoliation-Reassembly (ER) and (2) Coprecipitation (CO)). First of all, magnetite powder $(0.5 \mathrm{~g})$ was dispersed in $10 \mathrm{~mL}$ DI water through ultrasonication for 20 minutes.

2.3.1. Mag@LDH Nanocomposites via Exfoliation-Reassembly Method (Mag@LDH-ER). MgAl-LDH precursor was synthesized by conventional coprecipitation. Briefly, mixed metal nitrate solution $\left(0.063 \mathrm{~mol}\right.$ of $\mathrm{Mg}\left(\mathrm{NO}_{3}\right)_{2} \cdot 6 \mathrm{H}_{2} \mathrm{O}$ and $\left.0.0315 \mathrm{~mol} \mathrm{Al}\left(\mathrm{NO}_{3}\right)_{2} \cdot 9 \mathrm{H}_{2} \mathrm{O}\right)$ was titrated to $\mathrm{pH}$ of $\sim 9.5$ with alkaline solution $(0.21 \mathrm{~mol}$ of $\mathrm{NaOH})$ under vigorous stirring and $\mathrm{N}_{2}$ purging. The white precipitates were aged for 24 hours and then washed 4 times utilizing centrifugation $(10000 \mathrm{rpm}$, 10 minutes) and decarbonated water. Lyophilized MgAl-LDH powder $(0.5 \mathrm{~g})$ was dispersed in $500 \mathrm{~mL}$ formamide and stirred for 24 hours under $\mathrm{N}_{2}$ purging in order to exfoliate LDH nanolayers as previously reported [25].

To introduce LDH nanosheets on magnetite, $10 \mathrm{~mL}$ of magnetite suspension $(50 \mathrm{mg} / \mathrm{mL})$ was put into $50 \mathrm{~mL}$ of $\mathrm{NaHCO}_{3}$ solution $(0.006 \mathrm{~mol})$ and excess reactant was removed by centrifugation. Carbonate adsorbed magnetite suspension was then located in $50 \mathrm{~mL}$ of exfoliated $\mathrm{LDH}$ colloid $(1 \mathrm{mg} / \mathrm{mL})$ to introduce LDH nanosheets on carbonate adsorbed magnetite. The above two steps were repeated 10 times to increase LDH moiety on magnetite. The final product was washed thoroughly with DI water and lyophilized.

2.3.2. Mag@LDH Nanocomposites via Coprecipitation Method (Mag@LDH-CO). As-prepared magnetite suspension was sequentially treated with alkaline solution $(0.0007 \mathrm{~mol}$ of $\mathrm{NaHCO}_{3}$ and $0.0013 \mathrm{~mol}$ of $\mathrm{NaOH}$ in $15 \mathrm{~mL}$ ) and mixed metal solution $\left(0.0043 \mathrm{~mol}\right.$ of $\mathrm{Mg}\left(\mathrm{NO}_{3}\right)_{2} \cdot 6 \mathrm{H}_{2} \mathrm{O}$ and $0.0022 \mathrm{~mol}$ $\mathrm{Al}\left(\mathrm{NO}_{3}\right)_{3} \cdot 9 \mathrm{H}_{2} \mathrm{O}$ in $20 \mathrm{~mL}$ ) to promote coprecipitation of $\mathrm{LDH}$ on magnetite surface. At each step, centrifugation was utilized to separate solid part. The above steps were repeated 10 times to increase LDH moiety as in ER method. The obtained nanocomposite was collected by centrifugation and washed with DI water and lyophilized. 
2.4. Characterization. The crystal structures of magnetite, MgAl-LDH, and two kinds of Mag@LDH nanocomposites were investigated with $\mathrm{D} 2$ phaser $\mathrm{X}$-ray diffractometer (XRD) with $\mathrm{Ni}$-filtered $\mathrm{Cu}-\mathrm{K} \alpha$ radiation $(\lambda=1.5406 \AA)$ manufactured by Bruker AXS (Billerica, MA, USA). To identify primary particle size and morphology, scanning electron microscopy (SEM; FEI Quanta 250 FEG, FEI Company, Hilsboro, OR, USA) measurement was carried out. Each sample was suspended in $\mathrm{EtOH}(0.01 \mathrm{wt} / \mathrm{v} \%)$ and a drop of suspension was put on cleaned silicon wafer and dried in vacuum. Then, each sample was treated with $\mathrm{Pt} / \mathrm{Pd}$ plasma for 1 minute and images were collected by $30 \mathrm{kV}$ accelerated electron beam. For atomic force microscopy (AFM, NX10, Park Systems, Suwon, Korea), $0.00001 \mathrm{wt} / \mathrm{v} \%$ of EtOH suspension was utilized and suspension was dropped on silicon wafer as described in SEM specimen preparation. Thickness and surface line profile of samples were obtained with in noncontact mode. Surface roughness $\left(R_{a}\right)$ of each nanocomposite was calculated with Park system AFM XEI software. The zeta-potential values of pristine LDH and nanocomposites at $\mathrm{pH} 7$ were investigated by ELSZ-1000 (Otsuka Electronics Co., LTD., Hirakata, Japan) with disposable cell at $25^{\circ} \mathrm{C}$. Specific surface area was measured by $\mathrm{N}_{2}$ adsorptiondesorption isotherm with BELSORP-mini II (MicrotracBEL Corp., Osaka, Japan). Quantification of nanocomposite was carried out by inductively coupled plasma-optical emission spectrometer (ICP-OES; OPTIMA 7300 DV, Perkin Elmer, Waltham, MA, USA) after fully digesting sample with $10 \mathrm{M}$ $\mathrm{HCl}$ solution.

2.5. Evaluation of Chromate Removal Efficacy on Mag@LDH Nanocomposites with Respect to Contact Time, pH, and Concentration of Chromate Solution. For the time-dependent chromate adsorption experiments, each nanocomposite (100 mg of Mag@LDH-ER or Mag@LDH-CO) was dispersed into $50 \mathrm{~mL}$ of chromate solution $(50,100$, and $200 \mathrm{ppm}$ of initial concentration) and then gently shaken by Orbital Shaker SH30 (FINEPCR, Gunpo, Korea) at $25^{\circ} \mathrm{C}$. At the time points $0,0.5,1,2,3,4,6,12$, and 24 hours, nanocomposites were collected by magnetic separation and chromate concentration in supernatant was quantified with ultraviolet-visible spectrophotometer (UV-Vis; Shimadzu UV-1800, Shimadzu Corporation, Kyoto, Japan) at $\lambda_{\max }=372 \mathrm{~nm}$. In order to evaluate $\mathrm{pH}$ effect on chromate adsorption, initial $\mathrm{pH}$ of chromate solution (initial concentration of $50 \mathrm{ppm}$ ) was set to 2, 4, 5, 7, 9, and 11 utilizing $0.1 \mathrm{M} \mathrm{HCl}$ or $0.1 \mathrm{M} \mathrm{NaOH}$ solution, and then $100 \mathrm{mg}$ of nanocomposites was dispersed into the solution. After $24 \mathrm{~h}$, equilibrium $\mathrm{pH}$ and adsorbed amount of chromate was evaluated with $\mathrm{pH}$ meter and UV-Vis spectrophotometer, respectively.

2.6. Regeneration and Recyclability Test. To evaluate applicability of nanocomposites in practical water treatment, the regeneration and recyclability of nanocomposites in chromate removal were evaluated. In order to detach adsorbed chromate, chromate adsorbed nanocomposites were treated with $\mathrm{NaHCO}_{3}$ solution $(0.05 \mathrm{M}, 50 \mathrm{~mL})$ under stirring at room temperature for 6 hours. Thus, regenerated nanocomposites were collected by magnet and lyophilized. Then, the

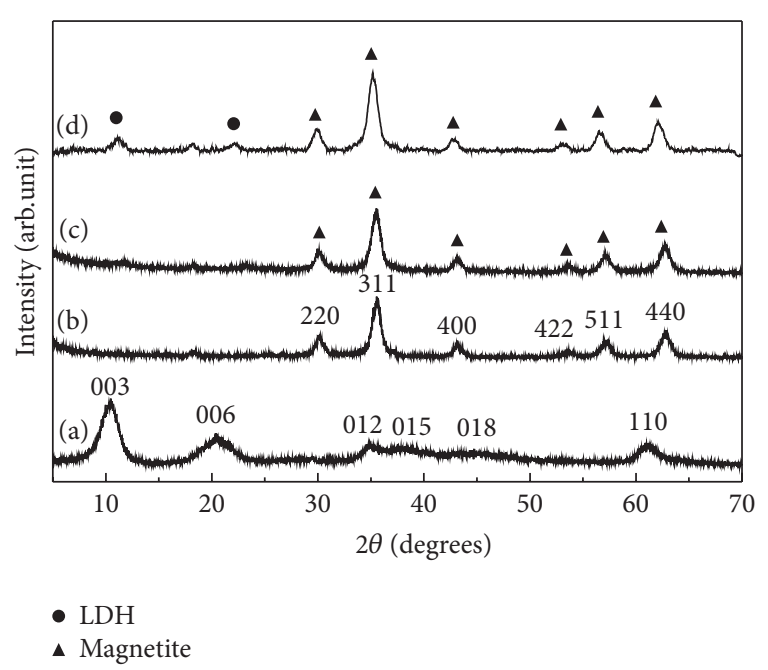

Figure 1: X-ray diffraction patterns of (a) MgAl-LDH, (b) magnetite, (c) Mag@LDH-ER, and (d) Mag@LDH-CO, respectively.

chromate adsorption experiment in Section 2.5 was repeated. Three cycles of adsorption test were carried out.

\section{Result and Discussion}

3.1. Characterization of Pristine LDH, Magnetite, and Two Nanocomposites, Mag@LDH-ER and Mag@LDH-CO. In order to identify the crystal structure of $\mathrm{LDH}$, magnetite, and their nanocomposites, XRD patterns were obtained (Figure 1). In Figure 1(a), the pristine MgAl-LDH showed well-developed $(00 l)$ diffraction indicating stacking of 2-dimensional nanosheets. Along with $(00 l)$ peaks, lattice peaks such as (012), (015), (018), and (110) at 35.0, 38.1, 45.0, and $61.3^{\circ}$ suggested successful development of hydrotalcite (JCPDS number 14-0191) phase as intended. The XRD pattern of $\mathrm{Fe}_{3} \mathrm{O}_{4}$ (Figure 1(b)) exhibited six characteristic peaks of inverse spinel structure of magnetite (JCPDS number 190629): (220), (311), (400), (422), (511), and (440) at 30.0, 35.1, $42.9,54.0,57.0$, and $61.8^{\circ}$, respectively. The nanocomposite between magnetite and LDH through exfoliation-reassembly, Mag@LDH-ER, only exhibited peaks of magnetite without those of LDH (Figure 1(c)). Random stacking of delaminated $\mathrm{LDH}$ nanosheets on magnetite surface was thought to result in reduction of crystallinity. Similar phenomenon was reported elsewhere; exfoliation-reassembly of layered nanomaterials in the presence of nanoparticles forms house-ofcards structure resulting in the loss of layered XRD patterns $[26,27]$. On the other hand, Mag@LDH-CO showed both X-ray diffraction patterns from LDH ((003) and (006): closed circles in Figure 1(d)) and magnetite ((220), (311), (400), (422), (511), and (440): closed triangles). It is expected that coprecipitation of LDH on magnetite resulted in ordered crystal growth rather than random stacking of nanosheets. XRD patterns containing both nanoparticle and LDH phase were reported in the synthesis of $\mathrm{CoFe}_{2} \mathrm{O}_{4} @ \mathrm{MgAl}-\mathrm{LDH}$ through coprecipitation [19].

According to SEM image (Figure 2), LDH and magnetite particles were determined to have irregular shape with 


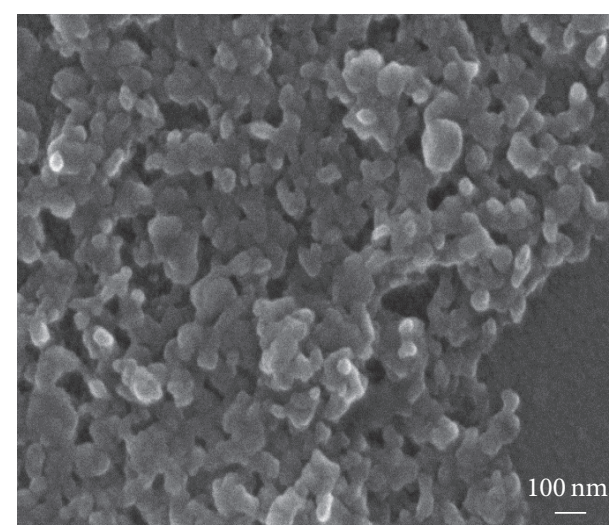

(a)

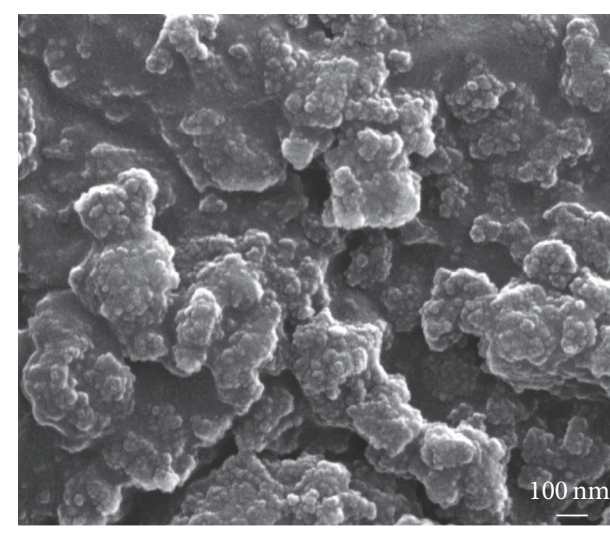

(c)

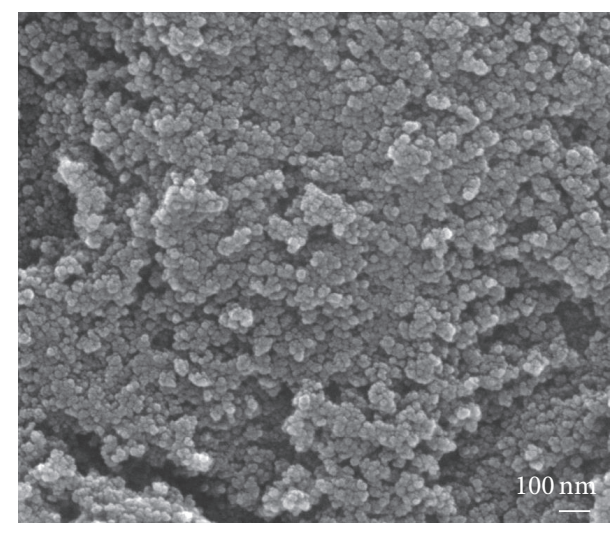

(b)

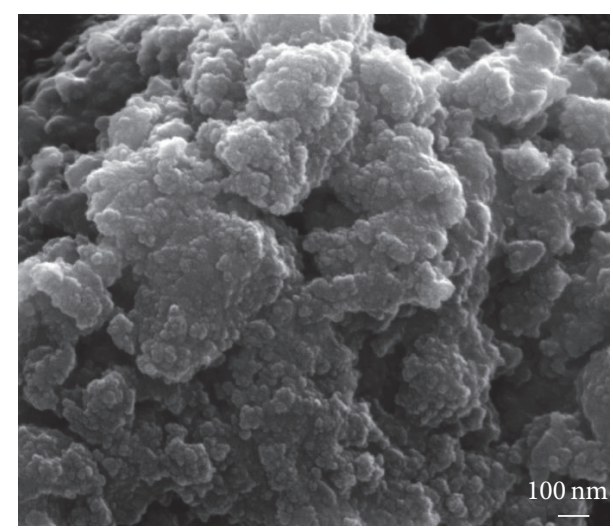

(d)

FIGURE 2: Scanning electron microscopic images of (a) MgAl-LDH, (b) magnetite, (c) Mag@LDH-ER, and (d) Mag@LDH-CO, respectively.

average diameters $\sim 50 \mathrm{~nm}$ and $\sim 30 \mathrm{~nm}$, respectively. The surface morphology of Mag@LDH-ER was smooth compared with that of Mag@LDH-CO which showed agglomeration of small particles. Such smooth surface of nanoparticles has been reported in the nanocomposite between nanoparticles and nanosheets, suggesting house-of-card structure developed by reassembled nanosheets $[26,28]$.

In order to observe lateral size, thickness, and roughness of single particles, AFM images were obtained with diluted nanocomposites compared with SEM specimen (Figure 3). In Figures 3(a) and 3(b), Mag@LDH-ER had $\sim 300 \mathrm{~nm}$ diameter and $\sim 90 \mathrm{~nm}$ thickness, and Mag@LDH-CO had $\sim 350 \mathrm{~nm}$ diameter and $\sim 40 \mathrm{~nm}$ thickness. The surface of Mag@LDH-ER was determined to be less rough $\left(R_{a}=\right.$ $7.67 \mathrm{~nm})$ than Mag@LDH-CO $\left(R_{a}=11.68 \mathrm{~nm}\right)$, which was corresponding to SEM observation. This result suggested that the LDH nanosheets covered magnetite nanoparticles in ERnanocomposite, whereas both $\mathrm{LDH}$ and magnetite nanoparticles were homogeneously mixed in CO-nanocomposite.

3.2. Quantification and Physicochemical Property Evaluation on Nanocomposites. In order to determine chemical formulae of two nanocomposites, we quantified metal content through ICP-OES. As summarized in Table 1, the chemical formulae of Mag@LDH-ER and Mag@LDH$\mathrm{CO}$ were $\left[\mathrm{Mg}_{2.52} \mathrm{Al}(\mathrm{OH})_{6.75}\left(\mathrm{CO}_{3}\right)_{0.5}\right]\left[\mathrm{Fe}_{3} \mathrm{O}_{4}\right]$ and $\left[\mathrm{Mg}_{1.81} \mathrm{Al}(\mathrm{OH})_{5.62}\left(\mathrm{CO}_{3}\right)_{0.5}\right]_{0.82}\left[\mathrm{Fe}_{3} \mathrm{O}_{4}\right]$, respectively, suggesting that slightly more LDH moiety was introduced by ER method. However, active adsorption site $\left(\mathrm{Al}^{3+}\right)$ per $\mathrm{g}$ nanocomposite was fairly similar for Mag@LDH-ER and Mag@LDH-CO. Specific surface area values were determined: 97.4 and $122.4 \mathrm{~m}^{2} / \mathrm{g}$ for Mag@LDH-ER and Mag@LDH-CO, respectively.

The average zeta-potential values were +20.78 and +9.52 mV for Mag@LDH-ER and Mag@LDH-CO, showing more positive surface charge on ER-nanocomposite. As shown in Figure 4, pristine LDH had highly positive charge $(+42.21 \mathrm{mV})$, while magnetite had negative charge $(-34.33 \mathrm{mV})$. Supposing that the LDHs sufficiently cover magnetite surface, the negative surface charge of magnetite would be camouflaged. The zeta-potential graph of Mag@LDH-CO lay from -50 to $+50 \mathrm{mV}$, clearly showing negatively charged region. In ER method, LDH nanosheets covered magnetite surface effectively to form particle-plate nanocomposite, as the nanosheets had larger lateral dimension $(\sim 50 \mathrm{~nm})$ than magnetite's diameter $(\sim 30 \mathrm{~nm})$. On the other hand, $\mathrm{LDH}$ nanoparticles formed in $\mathrm{CO}$ method were thought to be more particle-like rather than plate, which 

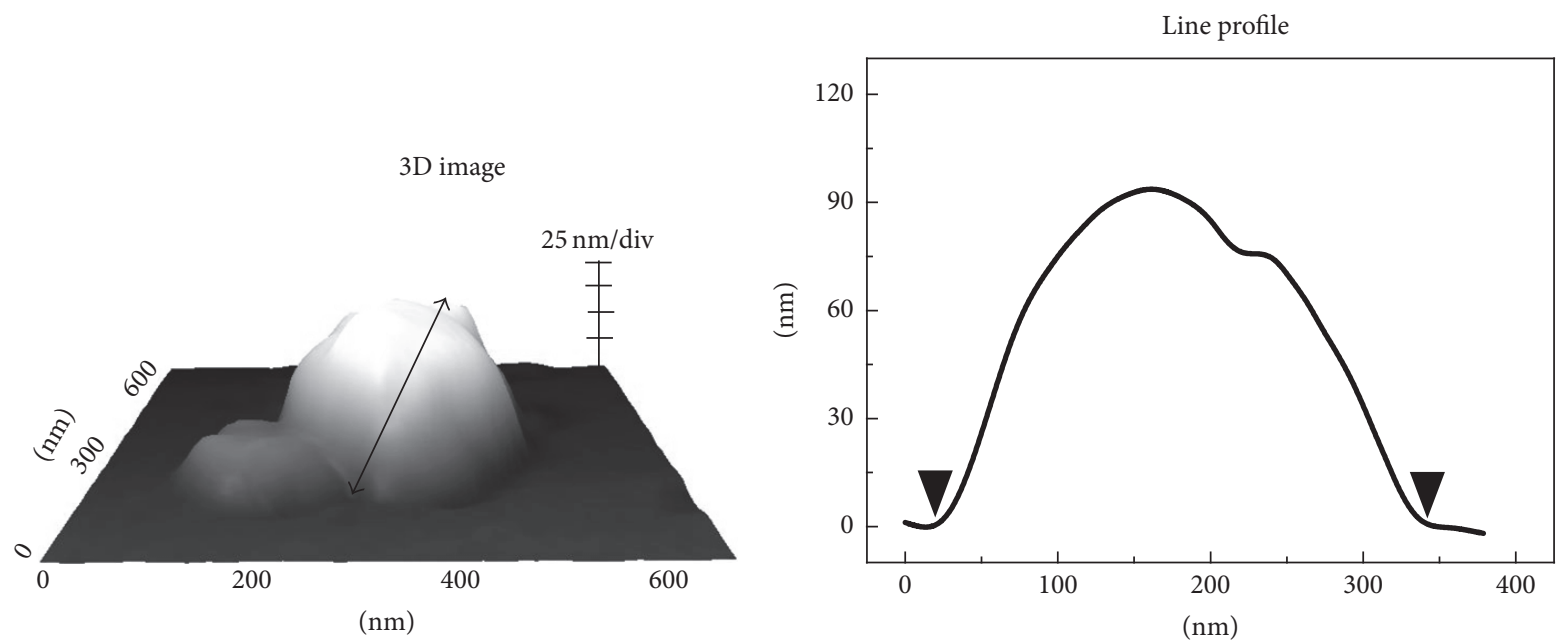

(a)
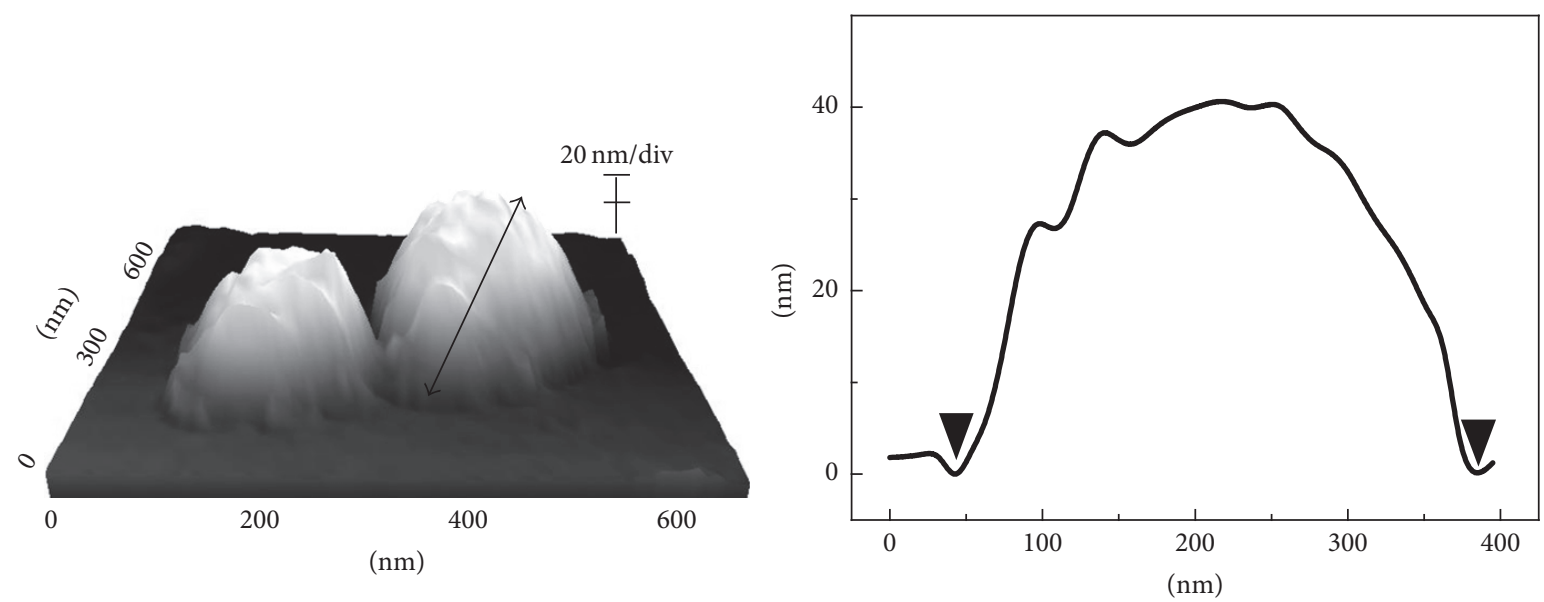

(b)

FIGURE 3: Atomic force microscopic 3D images and corresponding line profiles of (a) Mag@LDH-ER and (b) Mag@LDH-CO, respectively.

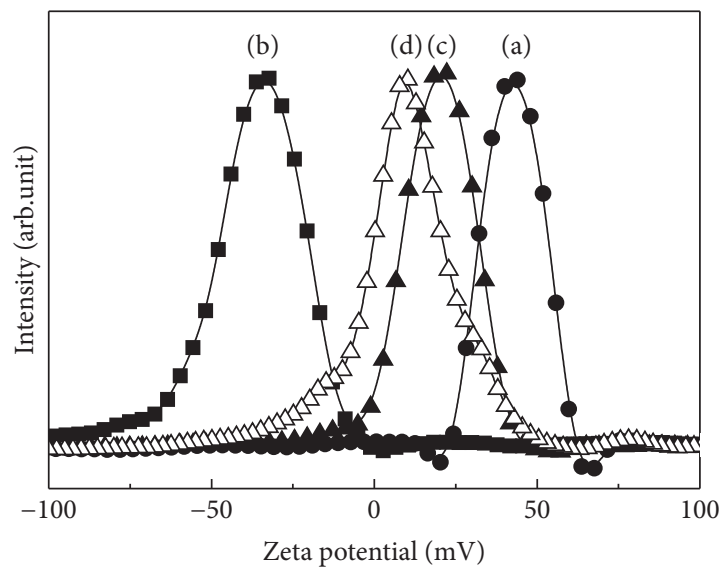

FIgURE 4: Zeta-potential distribution patterns for (a) MgAl-LDH, (b) magnetite, (c) Mag@LDH-ER, and (d) Mag@LDH-CO. 


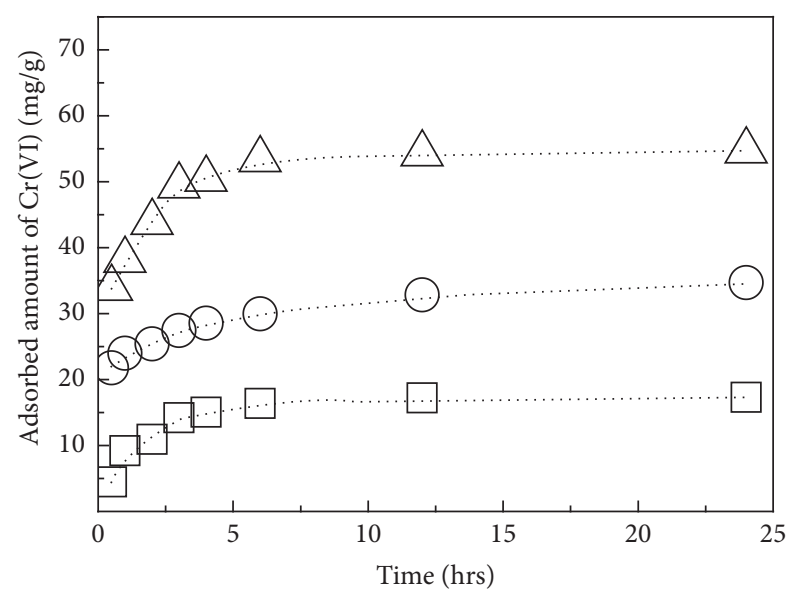

$$
\begin{aligned}
& \triangle 200 \mathrm{ppm} \\
& \bigcirc \cdot 100 \mathrm{ppm} \\
& \square .50 \mathrm{ppm}
\end{aligned}
$$

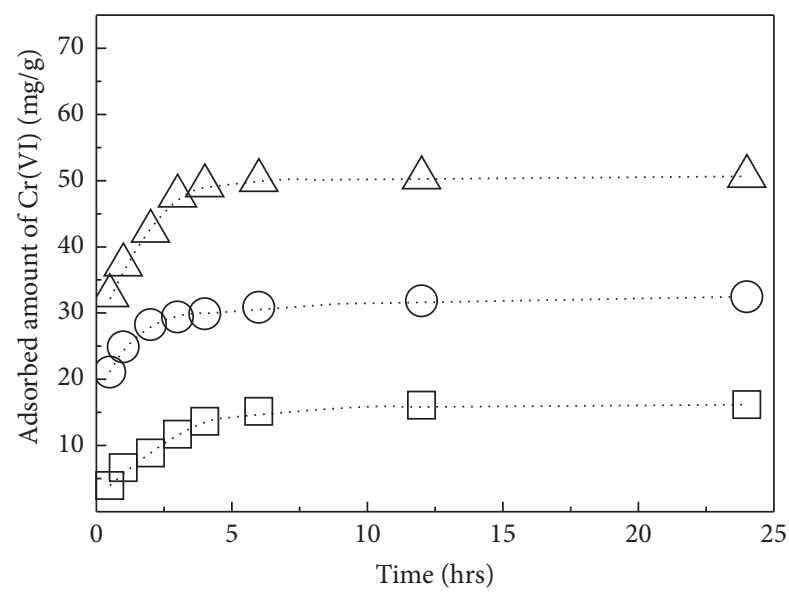

A. $200 \mathrm{ppm}$
$.100 \mathrm{ppm}$
․ $50 \mathrm{ppm}$

(a)

(b)

FIGURE 5: Time-dependent chromate adsorption amount (mg chromate/g nanocomposite) at different initial chromate concentrations for (a) Mag@LDH-ER and (b) Mag@LDH-CO. The experiments were carried out at pH 7.

TABLE 1: Quantification results and physicochemical properties of (a) Mag@LDH-ER and (b) Mag@LDH-CO.

\begin{tabular}{lcccc}
\hline Sample & Chemical formulae & $\mathrm{Al}^{3+} /$ nanocomposite $(\mathrm{mol} / \mathrm{g})$ & Specific surface area $\left(\mathrm{m}^{2} / \mathrm{g}\right)$ & Zeta potential $(\mathrm{mV})$ \\
\hline (a) & {$\left[\mathrm{Mg}_{2.52} \mathrm{Al}(\mathrm{OH})_{6.75}\left(\mathrm{CO}_{3}\right)_{0.5}\right]\left[\mathrm{Fe}_{3} \mathrm{O}_{4}\right]$} & 0.0022 & 97.4 & +20.78 \\
(b) & {$\left[\mathrm{Mg}_{1.81} \mathrm{Al}(\mathrm{OH})_{5.62}\left(\mathrm{CO}_{3}\right)_{0.5}\right]\left[\mathrm{Fe}_{3} \mathrm{O}_{4}\right]_{1.22}$} & 0.0021 & 122.4 & +9.52 \\
\hline
\end{tabular}

resulted in particle-particle nanocomposite between $\mathrm{LDH}$ and magnetite. The evolution of $\mathrm{LDH}$ phases in XRD (Figure 1), rough surface (Figures 2 and 3 ), and larger specific surface area of Mag@LDH-CO also corresponded to this hypothesis.

\subsection{Evaluation of Chromate Removal Efficacy of Nanocompos-} ites (Mag@LDH-ER and Mag@LDH-CO). Time-dependent chromate removal test at different initial chromate concentrations $(50,100$, and $200 \mathrm{ppm})$ was carried out for both nanocomposites and the results were displayed in Figure 5. The amount of adsorbed chromate increased according to the initial concentration of chromate. Saturated chromate removal efficacy of Mag@LDH-ER at equilibrium time $(\sim 24$ hours) was $17.30,34.71$, and $54.68 \mathrm{mg} \mathrm{Cr}(\mathrm{VI}) / \mathrm{g}$ nanocomposite at 50,100, and $200 \mathrm{ppm}$ of chromate solution, respectively. The removal efficacy of Mag@LDH-CO at $24 \mathrm{~h}$ was determined to $16.07,31.83$, and $50.65 \mathrm{mg} \mathrm{Cr}(\mathrm{VI}) / \mathrm{g}$ nanocomposite at 50,100 , and $200 \mathrm{ppm}$ of chromate, respectively. These results showed that the chromate removal efficacies of current nanocomposites were comparable or higher than previous reports as we described in Introduction $[16,17]$. Furthermore, considering that the current nanocomposites have less than $50 \mathrm{wt} \%$ of LDH content, the chromate removal ability of $\mathrm{LDH}$ moiety in the nanocomposites is thought fairly high.

Although the time and concentration dependent chromate removal of two nanocomposites seemed similar,
Mag@LDH-ER had approximately 10\% larger chromate adsorption ability than Mag@LDH-CO (Table 2). It should be noted that, in the adsorption of $\mathrm{LDH}$, both positive charge sites $\left(\mathrm{Al}^{3+}\right)$ and specific surface area values affected adsorption ability. From Table 1, we could calculate that Mag@LDHCO had 5\% less positive sites but 25\% larger surface area per gram than Mag@LDH-ER. Thus, the higher adsorption was expected with Mag@LDH-CO, which was not the case in our study. This discrepancy could be explained by the different nanostructure and surface charge of two nanocomposites. Mag@LDH-ER, in which LDH well covered magnetite nanoparticles to have more positive surface charge, facilitated chromate approach to the nanocomposites compared to Mag@LDH-CO, resulting in better chromate adsorption.

To analyze the adsorption rate in the overall adsorption process of chromate onto nanocomposites, the experiment data was fitted using pseudo-first-order (1) and pseudosecond-order kinetic (2) [29] models, with the respective kinetics equations defined as follows:

$$
\begin{aligned}
\log \left(Q_{e}-Q_{t}\right) & =\log Q_{e}-\frac{k_{1}}{2.303} t \\
\frac{t}{Q_{t}} & =\frac{1}{k_{2} Q_{e}^{2}}+\frac{1}{Q_{e}} t .
\end{aligned}
$$

$\left(Q_{e}(\mathrm{mg} / \mathrm{g})\right.$ and $Q_{t}(\mathrm{mg} / \mathrm{g})$ are the amounts of chromate adsorbed at equilibrium time at any instant of time, $t$, resp., 

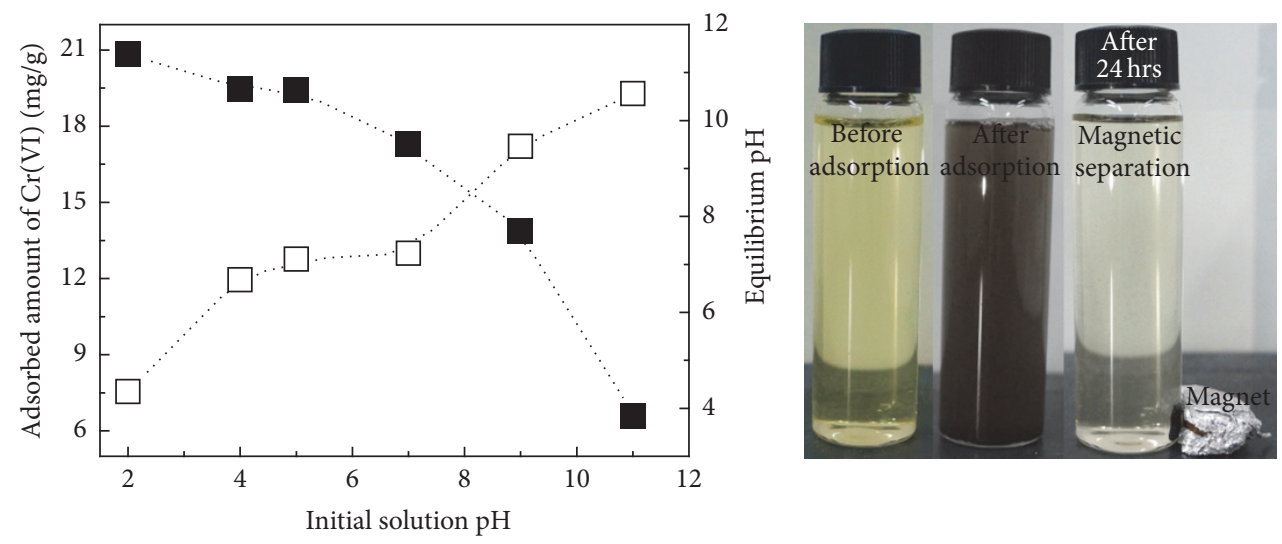

Adsorbed amount of $\mathrm{Cr}(\mathrm{VI})$

Equilibrium $\mathrm{pH}$

(a)

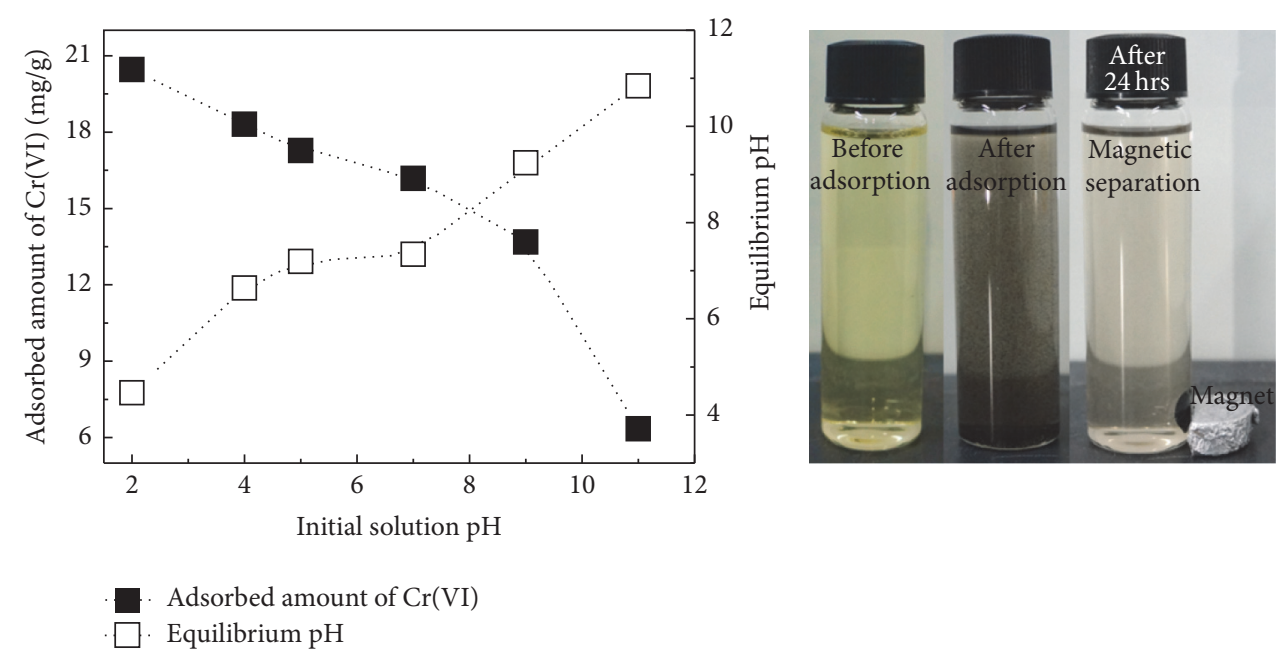

(b)

FIGURE 6: Effect of initial solution pH on Cr(VI) adsorption and equilibrium pH for (a) Mag@LDH-ER and (b) Mag@LDH-CO. The experiments were carried out at initial chromate concentration of $50 \mathrm{ppm}$. The photographs in the right side represent adsorption and separation of each nanocomposite at $\mathrm{pH} \sim 7$.

and $k_{1}\left(\mathrm{~min}^{-1}\right)$ and $k_{2}\left(\mathrm{~g}\left(\mathrm{mg}^{-1} \mathrm{~min}^{-1}\right)\right)$ are the rate constant of pseudo-first-order and pseudo-second-order kinetic model, resp.) The kinetic constants, $k_{1}$ and $k_{2}$, were determined from the slope of the linear plot of $\log \left(Q_{e}-Q_{t}\right)$ versus $t$ and $t / Q_{t}$ versus $t$, respectively. As represented in Table 2, the correlation coefficient $\left(R^{2}\right)$ obtained from the pseudo-second-order kinetic model $\left(R^{2} \geq 0.99\right)$ was higher than that obtained from the pseudo-first-order model $\left(R^{2}\right.$ was in the range of $0.91-$ $0.98)$, suggesting that the adsorption of chromate onto adsorbents followed pseudo-second-order kinetic. According to literatures [29], the rate determining step of LDH is chemical adsorption through sharing or exchange of electrons between the adsorbents and chromate rather than physical adsorption. $k_{2}$ values were similar for both nanocomposites, suggesting that the adsorption of both nanocomposites were mediated by LDH-based chromate adsorption. However, the overall adsorption amount was thought to be dependent on zetapotential value of nanocomposite, showing better adsorption on Mag@LDH-ER. According to time-dependent chromate adsorption study, we verified that the adsorption reached equilibrium after 24 hours.

Solution $\mathrm{pH}$ plays an important role in chromate adsorption owing to its effect not only on the degree of chromate speciation [30] but also on surface charge of the adsorbents. Figure 6 showed the results of chromate adsorption by nanocomposites with the initial solution $\mathrm{pH}$ ranging from $\sim 2$ to $\sim 11$ at initial solution concentration of $50 \mathrm{ppm}$. Equilibrium $\mathrm{pH}$ was fairly similar to initial $\mathrm{pH}$ above $\mathrm{pH} 7$ and lower than initial value below $\mathrm{pH}$ 7. The $\mathrm{pH}$ raising at acidic condition was attributed to the basic property of LDH moiety. The amount of chromate removal was highly dependent on $\mathrm{pH}$ showing gradual decrease from $20.83(\mathrm{pH} \sim 2)$ to $6.57 \mathrm{mg} / \mathrm{g}(\mathrm{pH} \sim 11)$ for Mag@LDH-ER and $20.45(\mathrm{pH} \sim 2)$ to $6.34 \mathrm{mg} / \mathrm{g}(\mathrm{pH} \sim$ 11) for Mag@LDH-CO.Chromate can have various speciation like $\mathrm{H}_{2} \mathrm{CrO}_{4}, \mathrm{HCrO}_{4}{ }^{-}, \mathrm{CrO}_{4}{ }^{2-}$, and $\mathrm{Cr}_{2} \mathrm{O}_{7}{ }^{2-}$; at low $\mathrm{pH}$, $\mathrm{HCrO}_{4}{ }^{-}$and $\mathrm{Cr}_{2} \mathrm{O}_{7}{ }^{2-}$ are prevalent, while $\mathrm{CrO}_{4}{ }^{2-}$ becomes 
TABLE 2: Adsorption parameters and kinetic fitting results for (a) Mag@LDH-ER and (b) Mag@LDH-CO.

\begin{tabular}{|c|c|c|c|c|c|c|}
\hline \multirow[t]{2}{*}{ Sample } & \multirow{2}{*}{$\begin{array}{l}\text { Initial concentration (ppm) } \\
\qquad C_{0}\end{array}$} & \multirow{2}{*}{$\begin{array}{c}\text { Adsorbed amount }(\mathrm{mg} \mathrm{Cr}(\mathrm{VI}) / \mathrm{g} \\
\text { nanocomposite }) \\
Q_{e} \\
\end{array}$} & \multicolumn{2}{|c|}{ Pseudo-first-order } & \multicolumn{2}{|c|}{ Pseudo-second-order } \\
\hline & & & $k_{1}$ & $R^{2}$ & $k_{2}$ & $R^{2}$ \\
\hline \multirow{3}{*}{ (a) } & 50 & 17.30 & 0.003 & 0.96 & 0.052 & 0.99 \\
\hline & 100 & 34.71 & 0.001 & 0.98 & 0.030 & 0.99 \\
\hline & 200 & 54.68 & 0.002 & 0.93 & 0.018 & 0.99 \\
\hline \multirow{3}{*}{ (b) } & 50 & 16.07 & 0.003 & 0.96 & 0.053 & 0.99 \\
\hline & 100 & 31.83 & 0.002 & 0.96 & 0.031 & 0.99 \\
\hline & 200 & 50.65 & 0.003 & 0.91 & 0.019 & 0.99 \\
\hline
\end{tabular}

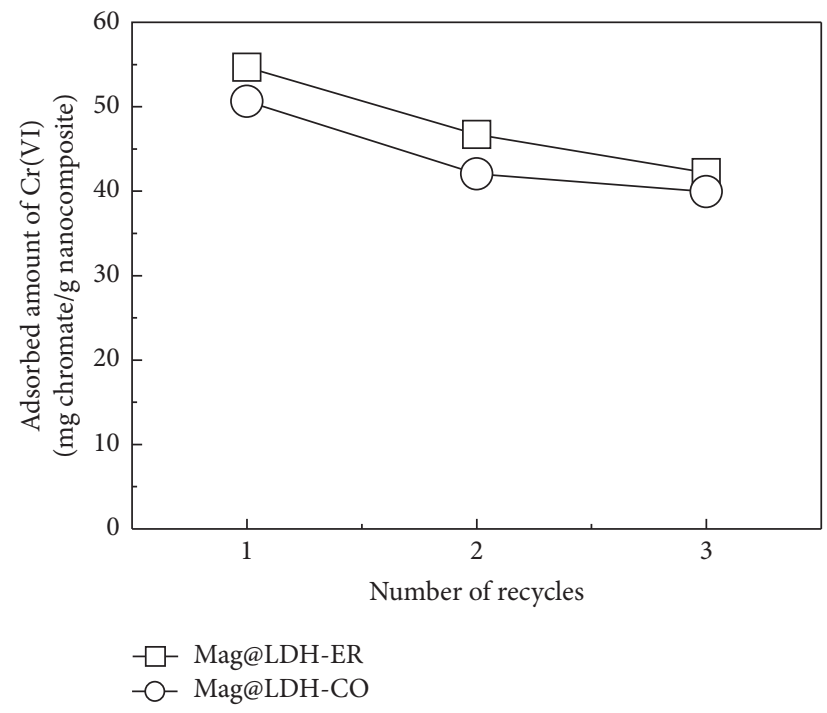

FIGURE 7: Adsorbed amount of chromate on Mag@LDH-ER and Mag@LDH-CO at each recycling step. The experiments were carried out at initial chromate concentration of $200 \mathrm{ppm}, \mathrm{pH} \sim 7$.

majority above $\mathrm{pH} 7$ [30]. According to the isoelectric point $\sim 9$ of LDH [31], the anionic adsorption ability of LDH could be significantly affected by the $\mathrm{pH}$ condition. At low $\mathrm{pH}$, less negative chromate species like $\mathrm{HCrO}_{4}{ }^{-}$exists, but highly positive surface charge of LDH can result in facilitated adsorption. The $\mathrm{pH}$ dependent property of chromate and $\mathrm{LDH}$ resulted in efficient chromate removal at low $\mathrm{pH}$ region. From the photographs in Figure 6, it was clearly observed that the adsorbent was quickly separated from the aqueous solution by an external magnet after adsorption process. Compared to previous reports $[19,20]$, these results showed that prepared nanocomposites can be considered to use as a good chromate removal materials with maintaining their magnetic property.

In order to utilize prepared nanocomposites into actual application, chromate adsorption test was repeated three times. For recycling nanocomposites, chromate was desorbed from the nanocomposites by treating in $\mathrm{NaHCO}_{3}$ solution $(0.05 \mathrm{M}, 50 \mathrm{~mL})$ under stirring at room temperature for 6 hours. From Figure 7, it was found that the adsorbed amount of chromate on nanocomposite remained high ( $80 \%)$ even in the third-regeneration cycle, although the adsorbed amount was slightly higher in Mag@LDH-ER at every recycling stage. This result suggested that the nanocomposites have the potential use as recyclable chromate scavenger in water treatment.

\section{Conclusion}

Nanocomposites consisting of magnetite nanoparticles and LDH nanosheets were prepared via two different methodologies. One is reassembly of exfoliated LDH nanosheets on magnetite nanoparticles (ER), and the other is generation of LDH on magnetite nanoparticles (CO), termed as Mag@LDH-ER and Mag@LDH-CO, respectively. According to XRD, SEM, AFM, and zeta-potential measurement, it was identified that LDH nanosheets covered surface of magnetite effectively in Mag@LDH-ER nanocomposite. On the other hand, LDH nanoparticles formed in $\mathrm{CO}$ method coexist with magnetite to make larger lumps than pristine particles. For evaluation of chromate removal efficacy, contact time, $\mathrm{pH}$, and concentration of chromate solutions were set as adsorption parameters. Mag@LDH-ER and Mag@LDH-CO showed maximum adsorption amount of 54.68 and $50.65 \mathrm{mg}$ $\mathrm{Cr}(\mathrm{VI}) / \mathrm{g}$ nanocomposite after 24 hours, suggesting slightly enhanced adsorption efficacy of ER-nanocomposite. Both nanocomposites showed similar $\mathrm{pH}$ dependent chromate adsorption behavior, decreasing adsorption upon increasing $\mathrm{pH}$. Kinetic and $\mathrm{pH}$ dependent studies revealed that $\mathrm{LDH}$ was the major adsorption sites for chromate in the nanocomposites. Easy collection and regeneration of both Mag@LDH nanocomposites were shown and adsorption capability was preserved $\sim 80 \%$ during three times of recycling. In conclusion, we could suggest that magnetite@LDH nanocomposites prepared by either coprecipitation or exfoliation-reassembly can be applied to the environmental remediating scavenger with recyclability.

\section{Competing Interests}

The authors declare that they have no competing interests.

\section{Authors' Contributions}

Gyeong-Hyeon Gwak and Min-Kyu Kim contributed equally to this work. 


\section{Acknowledgments}

This work was supported by a grant from Postharvest Research Project (PJ01050201) of Rural Development Administration (RDA), Nuclear R\&D Program (2015M2B2A4031430), and International Research \& Development Program (NRF-2014K1A3A1A21001297) through National Research Foundation of Korea (NRF) funded by the Ministry of Science, ICT and Future Planning.

\section{References}

[1] M. Shokouhimehr, Y. Piao, J. Kim, Y. Jang, and T. Hyeon, "A magnetically recyclable nanocomposite catalyst for olefin epoxidation," Angewandte Chemie, vol. 119, no. 37, pp. 7169-7173, 2007.

[2] O. V. Salata, "Applications of nanoparticles in biology and medicine," Journal of Nanobiotechnology, vol. 2, no. 1, article 3, 2004.

[3] F. Croce, G. B. Appetecchi, L. Persi, and B. Scrosati, "Nanocomposite polymer electrolytes for lithium batteries," Nature, vol. 394, no. 6692, pp. 456-458, 1998.

[4] H. Zhao and K. L. Nagy, "Dodecyl sulfate-hydrotalcite nanocomposites for trapping chlorinated organic pollutants in water," Journal of Colloid and Interface Science, vol. 274, no. 2, pp. 613-624, 2004.

[5] Y. Zheng, Y. Zheng, and R. Ning, "Effects of nanoparticles $\mathrm{SiO}_{2}$ on the performance of nanocomposites," Materials Letters, vol. 57, no. 19, pp. 2940-2944, 2003.

[6] M. Moniruzzaman and K. I. Winey, "Polymer nanocomposites containing carbon nanotubes," Macromolecules, vol. 39, no. 16, pp. 5194-5205, 2006.

[7] J. A. Prince, G. Singh, D. Rana, T. Matsuura, V. Anbharasi, and T. S. Shanmugasundaram, "Preparation and characterization of highly hydrophobic poly(vinylidene fluoride)—clay nanocomposite nanofiber membranes (PVDF-clay NNMs) for desalination using direct contact membrane distillation," Journal of Membrane Science, vol. 397, pp. 80-86, 2012.

[8] L. M. Veca, M. J. Meziani, W. Wang et al., "Carbon nanosheets for polymeric nanocomposites with high thermal conductivity," Advanced Materials, vol. 21, no. 20, pp. 2088-2092, 2009.

[9] S. I. Shin, A. Go, I. Y. Kim, J. M. Lee, Y. Lee, and S.-J. Hwang, "A beneficial role of exfoliated layered metal oxide nanosheets in optimizing the electrocatalytic activity and pore structure of Pt-reduced graphene oxide nanocomposites," Energy and Environmental Science, vol. 6, no. 2, pp. 608-617, 2013.

[10] J. M. Lee, I. Y. Kim, S. Y. Han, T. W. Kim, and S.-J. Hwang, "Graphene nanosheets as a platform for the 2D ordering of metal oxide nanoparticles: mesoporous $2 \mathrm{D}$ aggregate of anatase $\mathrm{TiO}_{2}$ nanoparticles with improved electrode performance," Chemistry-A European Journal, vol. 18, no. 43, pp. 13800-13809, 2012.

[11] S.-M. Paek, E. Yoo, and I. Honma, "Enhanced cyclic performance and lithium storage capacity of $\mathrm{SnO}_{2}$ /graphene nanoporous electrodes with three-dimensionally delaminated flexible structure," Nano Letters, vol. 9, no. 1, pp. 72-75, 2009.

[12] J.-H. Choy, S.-J. Choi, J.-M. Oh, and T. Park, "Clay minerals and layered double hydroxides for novel biological applications," Applied Clay Science, vol. 36, no. 1-3, pp. 122-132, 2007.

[13] J.-H. Choy, "Intercalative route to heterostructured nanohybrid," Journal of Physics and Chemistry of Solids, vol. 65, no. 2-3, pp. 373-383, 2004.
[14] H. Yang, C. Liu, D. Yang, H. Zhang, and Z. Xi, "Comparative study of cytotoxicity, oxidative stress and genotoxicity induced by four typical nanomaterials: the role of particle size, shape and composition," Journal of Applied Toxicology, vol. 29, no. 1, pp. 69-78, 2009.

[15] J.-M. Oh, S.-J. Choi, G.-E. Lee, S.-H. Han, and J.-H. Choy, "Inorganic drug-delivery nanovehicle conjugated with cancer-cellspecific ligand," Advanced Functional Materials, vol. 19, no. 10, pp. 1617-1624, 2009.

[16] K.-H. Goh, T.-T. Lim, and Z. Dong, "Application of layered double hydroxides for removal of oxyanions: a review," Water Research, vol. 42, no. 6-7, pp. 1343-1368, 2008.

[17] W. Wang, J. Zhou, G. Achari, J. Yu, and W. Cai, "Cr(VI) removal from aqueous solutions by hydrothermal synthetic layered double hydroxides: adsorption performance, coexisting anions and regeneration studies," Colloids and Surfaces A: Physicochemical and Engineering Aspects, vol. 457, no. 1, pp. 3340, 2014.

[18] X.-Y. Yu, T. Luo, Y. Jia et al., "Three-dimensional hierarchical flower-like Mg-Al-layered double hydroxides: highly efficient adsorbents for $\mathrm{As}(\mathrm{V})$ and $\mathrm{Cr}(\mathrm{VI})$ removal," Nanoscale, vol. 4, no. 11, pp. 3466-3474, 2012.

[19] L. Deng, Z. Shi, and X. Peng, "Adsorption of Cr(vi) onto a magnetic $\mathrm{CoFe}_{2} \mathrm{O}_{4} / \mathrm{MgAl}-\mathrm{LDH}$ composite and mechanism study," RSC Advances, vol. 5, no. 61, pp. 49791-49801, 2015.

[20] L.-G. Yan, K. Yang, R.-R. Shan, H.-Q. Yu, and B. Du, "Calcined $\mathrm{ZnAl}$ - and $\mathrm{Fe}_{3} \mathrm{O}_{4} / \mathrm{ZnAl}$-layered double hydroxides for efficient removal of $\mathrm{Cr}(\mathrm{VI})$ from aqueous solution," RSC Advances, vol. 5, no. 117, pp. 96495-96503, 2015.

[21] R.-R. Shan, L.-G. Yan, K. Yang et al., "Magnetic $\mathrm{Fe}_{3} \mathrm{O}_{4} / \mathrm{MgAl}$ $\mathrm{LDH}$ composite for effective removal of three red dyes from aqueous solution," Chemical Engineering Journal, vol. 252, pp. 38-46, 2014.

[22] G.-H. Gwak, M.-K. Kim, and J.-M. Oh, "Composites of quasicolloidal layered double hydroxide nanoparticles and agarose hydrogels for chromate removal," Nanomaterials, vol. 6, no. 2, article 25, 2016.

[23] S. J. R. Prabakar, Y.-H. Hwang, E.-G. Bae et al., " $\mathrm{SnO}_{2} /$ Graphene Composites with self-assembled alternating oxide and amine layers for high li-storage and excellent stability," Advanced Materials, vol. 25, no. 24, pp. 3307-3312, 2013.

[24] S.-M. Paek, J.-U. Jang, S.-J. Hwang, and J.-H. Choy, "Exfoliation-restacking route to Au nanoparticle-clay nanohybrids," Journal of Physics and Chemistry of Solids, vol. 67, no. 5-6, pp. 1020-1023, 2006.

[25] F. Leroux, M. Adachi-Pagano, M. Intissar, S. Chauvière, C. Forano, and J.-P. Besse, "Delamination and restacking of layered doublehydroxides," Journal of Materials Chemistry, vol. 11, no. 1, pp. 105-112, 2001.

[26] X.-L. Wu, L. Wang, C.-L. Chen, A.-W. Xu, and X.-K. Wang, "Water-dispersible magnetite-graphene-LDH composites for efficient arsenate removal," Journal of Materials Chemistry, vol. 21, no. 43, pp. 17353-17359, 2011.

[27] J. M. Lee, J. L. Gunjakar, Y. Ham, I. Y. Kim, K. Domen, and S.-J. Hwang, "A linker-mediated self-assembly method to couple isocharged nanostructures: layered double hydroxide$\mathrm{CdS}$ nanohybrids with high activity for visible-light-induced $\mathrm{H}_{2}$ generation," Chemistry - A European Journal, vol. 20, no. 51, pp. 17004-17010, 2014.

[28] H. Li, L. Deng, G. Zhu, L. Kang, and Z.-H. Liu, "Fabrication and capacitance of $\mathrm{Ni}^{2+}-\mathrm{Fe}^{3+} \mathrm{LDHs} / \mathrm{MnO}_{2}$ layered nanocomposite 
via an exfoliation/reassembling process," Materials Science and Engineering B: Solid-State Materials for Advanced Technology, vol. 177, no. 1, pp. 8-13, 2012.

[29] W. Rudzinski and W. Plazinski, "Kinetics of solute adsorption at solid/solution interfaces: a theoretical development of the empirical pseudo-first and pseudo-second order kinetic rate equations, based on applying the statistical rate theory of interfacial transport," Journal of Physical Chemistry B, vol. 110, no. 33, pp. 16514-16525, 2006.

[30] I. García-Sosa and M. Olguín, "Comparison between the Cr (VI) adsorption by hydrotalcite and hydrotalcite-gibbsite compounds," Separation Science and Technology, vol. 50, no. 17, pp. 2631-2638, 2015.

[31] Y. Zhang and J. R. G. Evans, "Alignment of layered double hydroxide platelets," Colloids and Surfaces A: Physicochemical and Engineering Aspects, vol. 408, pp. 71-78, 2012. 

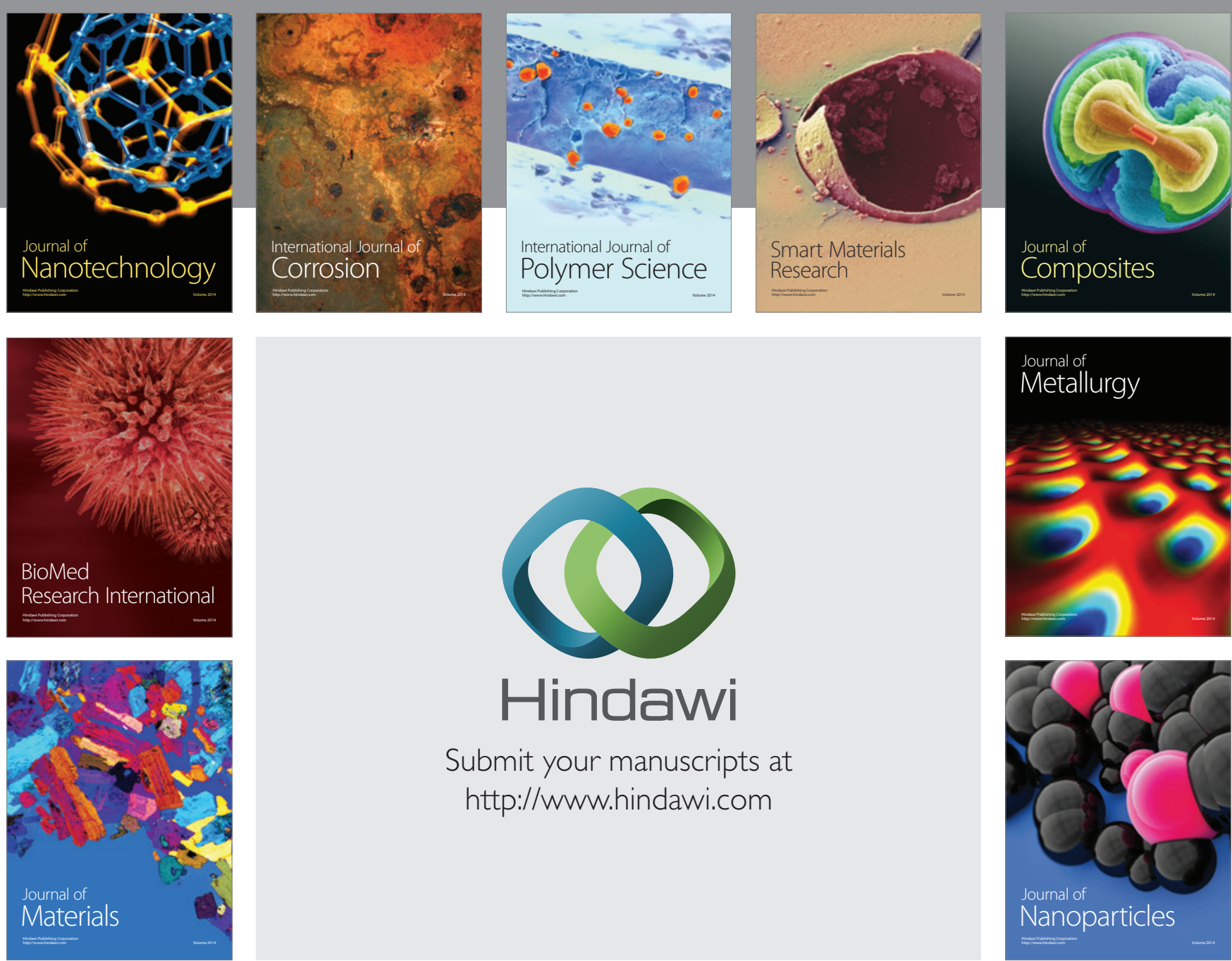

\section{Hindawi}

Submit your manuscripts at

http://www.hindawi.com

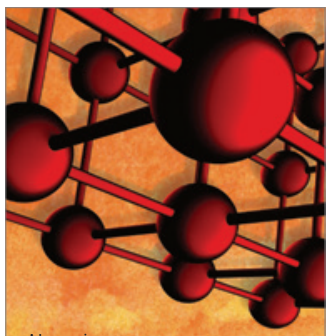

Materials Science and Engineering
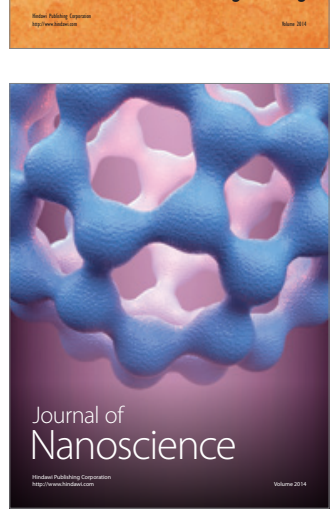
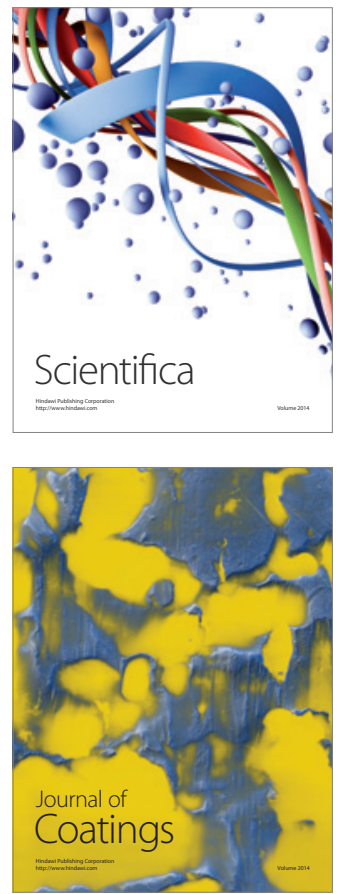
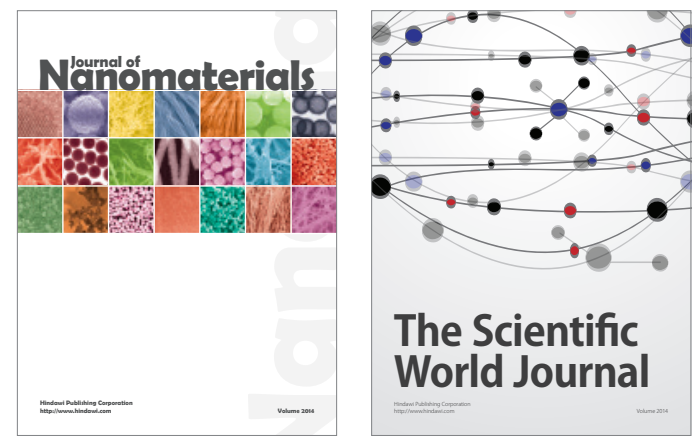

The Scientific World Journal
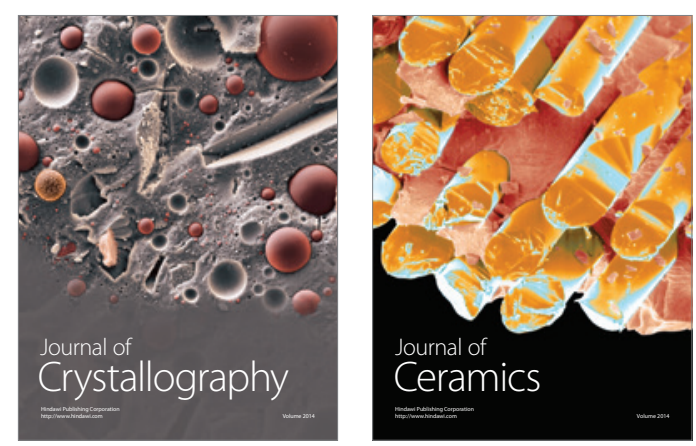
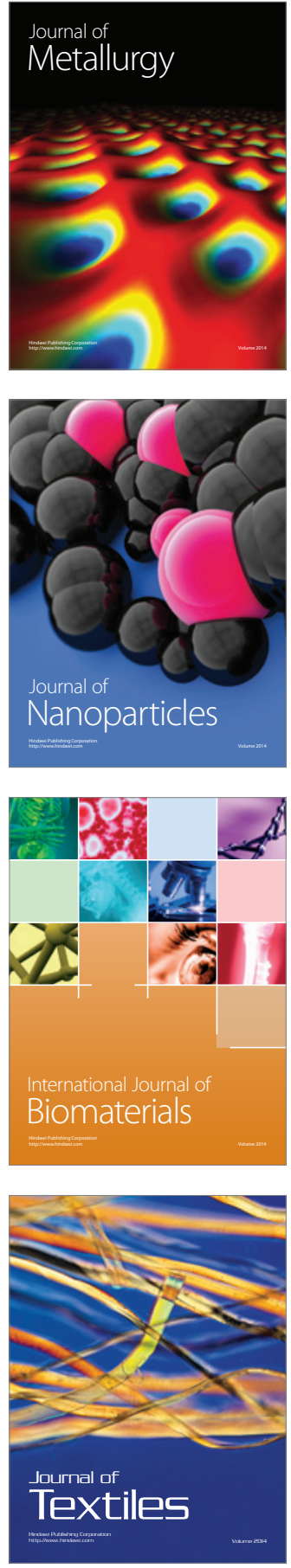